\title{
FRACTURE OF THE TRACHEA AND BRONCHUS
}

\author{
BY \\ JOHN DARK AND P. JEWSBURY \\ From the Thoracic Surgical Unit, Manchester Region
}

(RECEIVED FOR PUBLICATION DECEMBER 14, 1954)

Non-penetrating injuries of the main airways are of considerable rarity, but nevertheless there are many reported cases in the literature.

Kinsella and Johnsrud (1947) give an excellent review of the world literature, mentioning 38 cases, excluding two of their own. The first recorded recovery appears to be that of Krinitzki (1928), but since then there have been many successes including those of Sale (1954), Dalgleish, Hazen, and Kinnear (1954), Scannell (1951), Paulson (1951), Weisel and Jake (1953), and Kirkpatrick (1950). All these authors describe gross crushing accidents of the chest as the most common cause of this type of injury. The majority of the accidents referred to involve crushing of the patient's chest by a vehicle wheel or by heavy machinery. Clearly from such severe injuries many patients are killed outright or very soon die. Immediate survival is almost invariably associated with a haemopneumothorax and haemoptysis. A later development may be a stenosed bronchus with its attendant-atelectasis and bronchiectasis.

Such are the vagaries of medicine that in the following case none of the above features presented.

\section{CASE REPORT}

A 6-year-old schoolboy fell $10 \mathrm{ft}$. from a wall, on the evening of March 26, 1954, and as there were a few minor abrasions over the back of his right shoulder it was believed that this part struck the ground first. He got up and ran away, but after a few yards he became so breathless that he collapsed, and was subsequently urgently admitted to the nearest general hospital.

On examination he was found to be shocked and cyanosed and distressed, with only the minor abrasions to be seen externally. The mediastinum was displaced to the left and there was surgical emphysema over the neck and chest. The respirations were very rapid and the right hemithorax was tympanitic and breath sounds were absent over it.

A radiograph of the chest revealed no fractures of the ribs or sternum. The right lung was completely collapsed, and there was a total pneumothorax with mediastinal displacement to the left, and no fluid collection.
A traumatic tension pneumothorax was diagnosed and a small cannula connected to a water-seal bottle was inserted into the right chest (Fig. 1), and the boy was placed in an oxygen tent. A great deal of air blew off under pressure and continued to bubble off with each expiration, but little relief of his dyspnoea resulted.

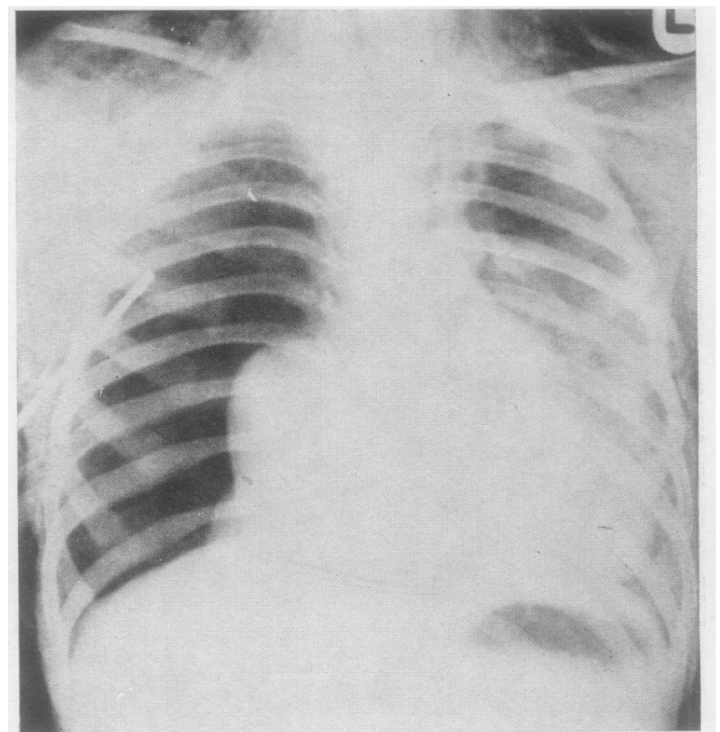

FIG. 1.-Pre-operative radiograph shows right tension pneumothorax in spite of intercostal cannula. Mediastinal displacement to the left and surgical emphysema of the neck and chest wall are well demonstrated.

This state of affairs continued for 24 hours, with some deterioration of his general condition and marked increase of the surgical emphysema. There was no radiological improvement. There was no haemoptysis at any stage.

At 8 p.m. on March 27 he was seen by one of us, when it was thought that the leak was so great that as a first step a larger tube should be inserted. This was done and certainly more air escaped, but there was no clinical improvement.

At this stage a fracture of the bronchus was diagnosed and it was decided that the only hope lay in an urgent thoracotomy, and, accordingly, he was transferred to the Thoracic Surgical Unit. 
OPERATION.-It was appreciated that here was a formidable anaesthetic problem and that positive pressure must be avoided if possible until the chest was opened. Therefore, the anaesthetist (Dr. T. Dinsdale) did not start until all was ready for a rapid thoracotomy. He induced with pentothal and curare and inserted an endotracheal tube. By the time the patient had been turned on to his left side he was deeply cyanosed, and when a rapid intercostal incision through the fifth space was made there was a gush of air under great pressure.

There was only a momentary improvement, for it was still not possible to produce any inflation of the lungs. The explanation for this soon became evident, for it was found that there was a $2 \mathrm{~cm}$. longitudinal slit at the lower end of the right side of the trachea. This slit extended into the site of origin of the right upper lobe bronchus which had been avulsed from the right main bronchus. A finger was applied to the opening and subsequently it became possible to inflate the left lung and the right lower and middle lobes. The child's condition now improved and it was not difficult to close the rent with interrupted fine silk sutures. A routine right upper lobectomy was then performed, and the wound was closed leaving a basal and an apical under-water drain. Postoperative bronchoscopy showed a dry bronchial tree.

A radiograph 12 hours later showed that the right lower and middle lobes had expanded and filled the

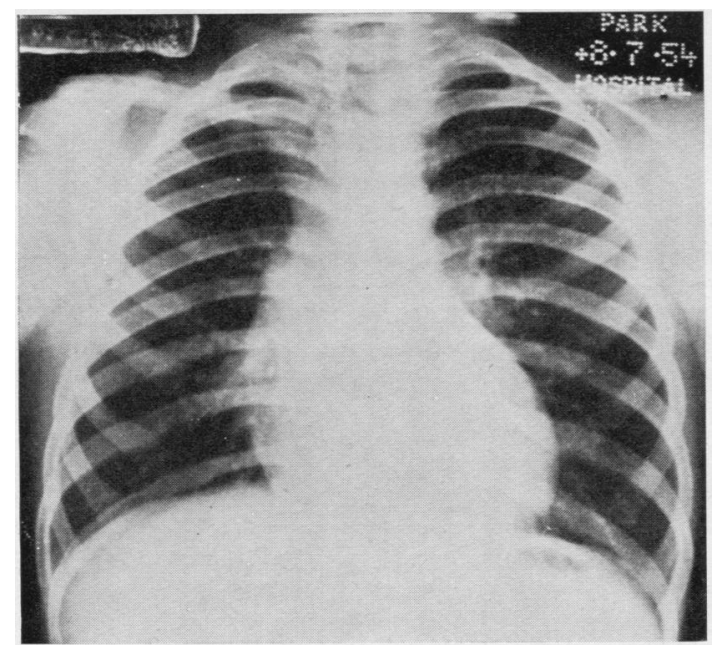

FIG. 2.-Follow-up radiograph shows minimal apical pleural thickening. The lung fields are otherwise clear and the mediastinal structures have returned to their normal position.

right hemithorax. A further bronchoscopy was carried out 24 hours later on account of sputum retention. Convalescence was then uneventful and the boy was discharged on the nineteenth day.

When seen four months later he was perfectly well and had returned to school.

\section{Discussion}

A search of the literature has not revealed any case of traumatic avulsion of the right upper lobe bronchus nor has tracheal injury been associated with a fracture of the bronchus to the best of our knowledge. The condition described was all the more surprising in view of the relative triviality of the accident. There are indeed no recorded cases of severe bronchial injury from non-penetrating trauma unassociated with severe crushing or a powerful blow.

Sale (1954) discussed the mechanism of bronchial injury and he enumerated four theories: (1) A simple shearing process acting on the lung; (2) compression of the bronchus against the vertebral column; (3) Schönberg (1912) pointed out that if the injury occurs at a time when the glottis is closed the airways are distended with air and are, therefore, more rigid ; (4) Kirkpatrick (1950) made the suggestion that depression of the sternum with the glottis closed may divaricate the main bronchi, thus fracturing them at their origin.

It is suggested that in the case under discussion the mechanism of injury was a shearing force applied to the right upper lobe in a downward direction when the glottis was closed.

Several authors point out that this type of injury is more likely to occur in the young owing to the flexibility of the thoracic cage.

Sanger (1945) in his review stated that if a tension pneumothorax cannot be controlled by needle aspiration, or intercostal catheter, a thoracotomy should be carried out immediately. It is clear that these conditions existed in the above case.

Re-anastomosis of a right main bronchus was carried out by Weisel and Jake (1953) in a most successful manner in an adult patient. This was not attempted in our case, owing to the small size of the avulsed bronchus and the desperate condition of the patient.

\section{SUMMARY}

A rare case of rupture of the trachea and right upper lobe bronchus with recovery is described. Some unusual features are recorded. The theories of its causation are discussed.

REFERENCES

Dalgleish, H. D., Hazen, G. M. T., and Kinnear, W. S. (1954). Canad. med. Ass. J., $70,45$.

Kinsella, T. J., and Johnsrud, L. W. (1947). J. thorac. Surg., 16, 571.

Kinsella, T. J., and Johnsrud, L. W. (1947). J. thorac.
Kirkpatrick, E. R. G. (1950). Brit. J. Surg., 37, 362.

Kirkpatrick, E. R. G. (1950). Brit. J. Surg., 37, 362.

Paulson, D. L. (1951). J. thorac. Surg., 22, 636.

Sale, T. A. (1954). Brit. J. Surg., 41, 625.

Sanger, P. W. (1945). Ann. Surg., 122, 147.

Scannell, J. G. (1951). Ibid., 133, 127.

Schönberg, S. (1912), Berl. klin. Wschr., 49, 2218

Weisel, W., and Jake, R. J. (1953). Ann. Surg., 137, 220. 